\title{
Entre negociação e conflito: gênero e coerção sexual em três capitais brasileiras
}

\author{
Negotiation and conflict: gender and sexual coercion \\ in three Brazilian capitals
}

Fabíola Cordeiro ${ }^{1}$

M aria Luiza Heilborn ${ }^{1}$

Cristiane da Silva Cabral ${ }^{1}$

Cláudia Leite de M oraes ${ }^{2}$

\footnotetext{
${ }^{1}$ Programa em Gênero,

SexualidadeeSaúde,

Instituto de Medicina

Social, U niversidade do

Estado do Rio de Janeiro.

Rua São Francisco Xavier

524/Bloco E/Sala 6013,

M aracanã. 20550-013 Rio

deJaneiro RJ.

fabiolacms@ims.uerj.br

2 Programa de Investigação

Epidemiológica da

Violência Familiar,

Instituto de M edicina

Social, Universidade do

Estado do Rio deJaneiro.
}

Abstract Thisarticlediscusses sexual coercion based on a population survey data, collected between 2001 and 2002, in three Brazilian capitals (Rio de Janeiro, Salvador e Porto Alegre) - Gravad Research. The results presented refer to questions about aspects of sexual negotiation, taken as possi ble experiences to be identified as sexual coercion, as well as youth values and opinions concerned to sexuality. The interviews were applied to males and females aged 18-24. Analysis of the empirical data points to the importance of specific scripts and to local dynamics and beliefs in the sexual interaction between genders in terms of identifying some behaviors as ways of forced sex. We aim to relativize the notion of violence that is much present in great part of the international literature about this theme.

Key words Sexual coercion, Sexual negotiation, Gender relations, Sexuality, Violence
Resumo Este artigo aborda a temática da coerção sexual a partir de dados coletados, entre os anos de 2001 e 2002, pelo inquérito populacional realizado em três capitais brasileiras (Rio de Janeiro, Salvador e Porto Alegre), na etapa quantitativa da pesquisa Gravidez na adolescência: estudo multicêntrico sobrejovens, sexualidadeereprodução no Brasil (GRAVAD). Os resultados aqui apresentados se referem às perguntas do questionário de entrevistas que contemplaram aspectos das práticas de negociação em torno do sexo, as experiências passíveis de serem identificadas como coerção sexual e valores sexuais dos jovens entrevistados. O sinformantes eram homense mulheres, entre 18 e 24 anos. A análise do material aponta a importância dos contextos específicos de interação e das dinâmicas e conven ções locais de interação sexual entre os gêneros na configuração de determinados comportamentos enquanto formas de sexo forçado. Busca-se assi m relativizar a noção positivada de violência presente em parte da literatura internacional sobre o tema.

Palavras-chave Coerção sexual, N egociação sexual, Relações de gênero, Sexualidade, Violência 


\section{Introdução}

A incorporação da sexualidade à pauta dos direitos humanos e 0 volume crescente de pesquisas internacionais cujos resultados questionaram dados oficiais acerca da magnitude das violências envolvendo atos tidos como sexuais conduziram à problematização de situações no âmbito das relações familiares e íntimas antes não discutidas ${ }^{1,2}$. Tais experiências adquiriram visibilidade no debate internacional como epi sódios de violência sexual. N esse contexto, a coerção sexual surge como uma das categorias elaboradas na tentativa de contemplar a maior complexidade e variedade possíveis de relações e cenários que envolvem atos contra a liberdade sexual e experiências de sexo forçado ${ }^{3,4}$. Esse tema tem recebido atenção de pesquisadores - sobretudo norte-americanos -, nas áreas da sociologia, da chamada sex research e, em especial, da saúde pública.

A coerção sexual tende a ser caracterizada em um continuum de distintos comportamentos, atitudes e práticas com variadas consequências, se traduzindo em restrições ao exercício da vontade individual $^{5}$. $\mathrm{N}$ a literatura internacional, essa categoria abrangente é frequentemente utilizada em referência a contatos e/ou intercursos sexuais obtidos mediante constrangimentos, como pressão verbal (insistência), chantagens, uso de força físi$\mathrm{ca}^{4 \cdot 9}$. Há também pesquisas em que o sexo consentido sem desejo e mediante falsas promessas e mentiras é tido como forçado ${ }^{5,10,11}$, o que expressa bem a polissemia do termo.

$\mathrm{Na}$ tentativa de restringir o escopo da categoria, pesquisadores têm utilizado técnicas de mensuração que buscam acessar comportamentos específicos que variam em intensidade ${ }^{7,9}$ - como 0 Sexual Experiences Survey (SES) ${ }^{12}$. Em geral, as investigações privilegiam o uso de métodos quantitativos de coleta de dados na abordagem do tema, predominando 0 uso de questionários estruturados ou semi-estruturados e, por vezes, auto-aplicados. No campo da saúde pública, os distintos desenhos dados às pesquisas tendem a ser encarados como um problema que dificulta a obtenção de estimativas acerca da magnitude do fenômeno ea comparabilidade en tre realidades sociais ${ }^{4,13}$. Há preocupação em construir uma categoria passível de ser utilizada transculturalmente, de modo a estabelecer parâmetros metodológicos universais de medição dessa modalidade de violência. Contudo, tal postura conduz ao obscurecimento do caráter relacional e situacional do que pode ser classificado como violência em distintos contextos.
Uma modalidade deviolência contra mulheres?

0 debate sobre coerção sexual centra-se majoritariamenteem episódios contra mulheres adultas eadolescentes ${ }^{2,3}$. A pesar dealgumas poucas investigações recentes americanas terem abordado a questão entre parceiros de mesmo sexo - sobretudo, com foco em pessoas inseridas no sistema prisional ${ }^{14,15}-0$ sexo forçado ou por constrangimento continua a ser tratado como uma realidade heterossexual. Pre domina um viés feminista que atrela a violência de gênero à heterossexualidade, como um dos desdobramentos da "dominação masculina"1,3.

Gagnon ${ }^{1}$ ressalta que, desde a década de oitenta, no âmbito dos estudos feministas norteamericanos, a perspectiva do construcionismo social e a noção de roteiros sexuais resultaram em propostas teóricas que enfatizavam que o modo como estão estruturadas as relações de gênero informa os cenários culturais e os roteiros interpessoaiseintrapsíquicos de conduta sexual. N essesentido, a assimetria de poder entre os gêneros no mundo social repercutiria em uma constante vulnerabilidade feminina em suas relações com os homens em distintos níveis, inclusive no domínio sexual ${ }^{8}$. De forma similar, investigações sociológicas sugeriram que a socialização tradicional ao imputar papéis e expectativas diferenciadas a homens e mulheres, constituindo um "duplo padrão moral" nas relações afetivo-sexuais, contribui para

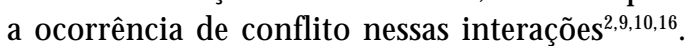
Embora nesses estudos também prevaleça a noção de que 0 aprendizado da sexualidade é condicionado pela lógica relacional de gênero, o foco não recai na idéia de repressão e controle sobre as muIheres, mas no tipo de relacionamento entre os sujeitos em interação enos distintos roteiros quea violência engendra, tendo em vista as expectativas de gênero $0^{1,10,16,17}$. A premissa é que 0 "duplo padrão moral" ao orientar os roteiros heterossexuais implicaria percepções distintas por gênero acerca do grau de intimidadeesperado edesejado entre parceiros, podendo propiciar a ocorrência deeventos coercitivos.

No final da década de oitenta, inquéritos com população universitária ou geral assinalaram casos de coerção reportados por homens, o que conduziu a uma ampliação do debate para além da tônica da vitimização feminina ${ }^{6,7,18}$. A literaturaque tem abordado as experiências masculinas aponta uma ocorrência de 10\% a 45\% de coerção sexual entre estudantes americanos de ensino médio e superior ${ }^{17}$. Tais pesquisas destacam estratégias de coerção sexual que prescindem do uso de força 
física e evidenciam os limites deenunciação da vontade em contextos nos quais a recusa a fazer sexo pode acarretar custos sociais significativos para os sujeitos $^{2,6}$. Ao contemplar as experiências de homens e mulheres como autores e alvos de constrangimento sexual, esses estudos demonstraram que considerar a assimetria de gênero e a maior vulnerabilidade das mulheres nas análises não significa ignorar que elas também são sujeitos de suas ações, participando ativamente dos jogos amorosos e sexuai $5^{3,19}$. Todavia, deve-se destacar que os homens tendem a relatar formas de coerção sexual consideradas mais brandas (sem uso de força física, por exemplo) $)^{3,7}$ e que, raramente, relatam prejuízos à saúde ou vivenciam esses eventos enquanto episódios de vitimizaçãa ${ }^{7}$.

No Brasil, a coerção sexual - tal como vimos definindo - éum objeto de pesquisa praticamente inexplorado. A penas três trabalhos abordaram diretamente essa temática: a investigação epidemiológica de Reichenheim eM oraes ${ }^{13}$, que pesquisou distintas modal idades de violência no contexto de relacionamentos íntimos a partir de dados coletados em maternidades de três hospitais públicos na cidade do Rio de Janeiro; 0 estudo de Moraes et al. ${ }^{20}$, que caracterizou e estimou a magnitude do problema entrejovens (moças erapazes, de 18 a 24 anos) de três capitais brasileiras; e a investigação sócio-antropológica de Cordeiro ${ }^{3}$ acerca das narrativas sobre sexo contra vontade de jovens de ambos os sexos residentes nessas mesmas capitais. As duas últimas investigações citadas derivam da pesquisa mais ampla Gravidez na adolescência: estudo multicêntrico sobre jovens, sexualidade e reprodução no Brasil (GRAVAD), que abordou o exercício da sexualidade eeventos reprodutivos nastrajetórias de jovens residentes em Salvador, no Rio de Janeiro e em Porto Alegre. Equipes de pesquisa de três universidades brasileiras (Programa em Gênero, Sexualidade e Saúde/IM S/UERJ, M USA/ ISC/ UFBA e NUPACS/UFRGS) empreenderam o estudo, que contou com uma etapa qualitativa (1999-2000), na qual foram realizadas 123 entre vistas em profundidade, e uma etapa quantitativa (2000-2001), que constou de um inquérito populacional com 4.634 jovens nas três capitais.

As análises de Moraes et al. ${ }^{20}$ e Cordeiro ${ }^{3}$ demonstram que o gênero é uma variável sociológica central para investigar aspectos das carreiras afetivo-sexuais e as experiências a elas correlacionadas de constrangimento e violência.

Esses estudos demonstram que 0 entendimento de tais eventos apenas é possível quando consideramos as formas pelas quais a gramática de gê nero modela as condutas e as trajetórias sociais.
N este artigo, examinamos dados ainda inexplorados sobre desacordos na negociação sexual e sexo contra vontade coletados na fase quantitativa da pesquisa GRAVAD. 0 objetivo é apontar a multiplicidade de sentidos envolvida em práticas caracterizadas como coerção sexual, sob a perspectiva dos valores sexuais e das negociações em torno do exercício da heterossexualidade.

\section{Aspectos metodológicos \\ elimitações da pesquisa}

\section{Sobre o inquérito populacional GRAVAD}

0 inquérito GRAVAD foi realizado por amostra probabilística estratificada, visando reproduzir na amostra a realidade sociodemográfica da população jovem, de 18 a 24 anos, das cidades em exame. A escolha por não trabalhar apenas com jovens que pudessem ser classificados como adolescentes, segundo os parâmetros da Organização Mundial da Saúde (OM S) - faixa etária de 10 a 19 anos -, atendeu ao interesse do estudo em acessar desdobramentos da gravidez na adolescência nas trajetórias dos informantes que tiveram tal experiência, em contraste com os que não vivenciaram esse evento. A amostra inicialmentedefinida foi de 4.500 domicílios nas três cidades, tendo em vista o índice sobregravidez na adolescência indicado pela Pesquisa Nacional em Demografia e Saúde referente ao ano de $1996^{21}$. Em cada cidade, as entrevistas foram distribuídas entre 55 setores censitários - unidades operacionais básicas definidas pelo Instituto Brasileiro de Geografia e Estatística (IBGE) para a realização de censos demográficos, - e 33 domicílios por setor. Cada setor censitário foi agrupado em cinco estratos, de acordo com a situação socioeconômica de seus habitantes, considerada a partir da renda média e dos anos de escolaridade do chefe do domicílio.

A estratificação da amostra se deu em três estágios: primeiro, foi selecionada uma amostra de setores estratificados; em seguida, uma amostra de domicílios em cada setor; e, finalmente, a seleção de uma pessoa em cada domicílio para participar do estudo ${ }^{21}$. Os censos demográficos de $1991 \mathrm{e}$ 2000 serviram de referência na seleção do número de setores por estrato. A amostragem dos setores censitários foi empreendida por seleção aleatória proporcional ao número de jovens na faixa etária de interesse. A seleção dos informantes ocorreu também por sorteio aleatório, com auxílio de um programa estatístico. Em domicílios onde havia mais de um jovem (moça ou rapaz) entre 18 e 24 
anos, optou-se por escolher aquele que fez/faria aniversário primeiro naquele ano civil (2001). Definiu-se que, em caso de coincidências na data de aniversário de moradores de uma mesma residência, o critério utilizado seria a ordem alfabética do primeiro nome ${ }^{21}$.

0 questionário estruturado epadronizado para coleta de dados nas três cidades (Rio de Janeiro, Salvador e Porto Alegre) foi elaborado a partir dos resultados da etapa precedente do estudo, em que foram realizadas 123 entrevistas em profundidade com jovens da mesma faixa etária residentes nessas cidades. Tal procedimento permitiu a formulação de um questionário culturalmente mais ade quado à realidade social dos informantes. A coleta de dados se deu em entrevistas face a face conduzidas por pesquisadores treinados, a maioria cursando pós-graduação em ciências sociais ou saúde coletiva. As 336 questões do questionário contemplavam informações sociodemográficas, origem e composição familiar, trajetória de estudo e trabaIho, trajetória afetivo-sexual, atitudes evalores sobre sexualidade, e gravidez e desdobramentos. 0 tempo médio de aplicação foi de 42 minutos e o índice de resposta foi de $85,2 \%$, contabilizando 4.634 entrevistas ( $52,8 \%$ dos participantes eram moças e $47,2 \%$, rapazes).

A amostra observada nas cidades estudadas abrangeu 1.442 jovens em Porto Alegre, 1.528 no Rio de Janeiro e 1.664 em Salvador. Para avaliação da significância estatística, utilizou-se o teste quiquadrado de Pearson corrigido para o efeito de desenho. 0 programa Stata 8.0 (Stata Corporation, CollegeStation, Estados Unidos) foi usado para o processamento e análise de dados. A pesquisa foi aprovada pelos comitês de ética em pesquisa das três universidades brasileiras envolvidas no proje to e todos os entrevistados concordaram em assinar o termo de consentimento livre e esclarecido aprovado pelos comitês, em respeito aos princípios éticos encampados pela declaração de H elsinki e pela Resolução 196/96 do Conselho Nacional de Ética em Pesquisa.

\section{Definindo o espectro deste estudo}

A pesquisa GRAVAD buscou acessar eventos de coerção sexual diretamente pela pergunta "Alguém já tentou forçar você a ter relações sexuais contra vontade?" A questão era seguida por perguntas que buscavam precisar o momento das trajetórias dos sujeitos em que a situação ocorreu, 0 tipo de constrangimento, o desdobramento do evento (se ocorreu ou não o intercurso sexual,) e o vínculo entre o/a informante e a pessoa que o/a coagiu. Contudo, outras questões do roteiro acerca de atitudes e valores sobre sexual idade também permitem apreender esse tipo de experiência:

- Já houve ocasiões em que, durante a relação sexual, vocêsesentiu pressionado pelas/pelos suas/ seus parceiros/as a fazer com elas/eles coisas que você não gosta?

- Já houve ocasiões em que você desejava ter relações sexuais e sua/seu parceira/o não? N a últimavez queisso aconteceu, você: 1 . insistiu; 2 . obrigou; 3. seduziu; 4. ficou quieto/a; 5 . procurou saber 0 que estava acontecendo; 6 . outro; 66 . recusou-se a responder; 77. não sabe; 88. NSA (não se aplica).

- Já houve ocasiões em queal gum/al guma parceira/o desejava ter relações sexuais e vocênão? $\mathrm{Na}$ última vez queisso aconteceu, ela/ele: 1 . insistiu; 2. obrigou; 3 . seduziu; 4. ficou quieto/a; 5 . procurou saber o que estava acontecendo; 6 . outro; 66 . recusou-se a responder; 77. não sabe; 88. N SA (não se aplica).

Essas perguntas abordam situações de coerção sexual de modo mais sutil e apreendem como os informantes lidam com a recusa do sexo em suas relações. Contemplam, assim, a questão da negociação sexual que, apesar de central ao modo como se desenrolam as relações sexuais, tende a receber menor atenção em muitas pesquisas sobre sexualidade.

Cabe salientar que investigar experiências frequentemente caracterizadas pela literatura contemporânea como coerção sexual implica discutir as possibilidades e dinâmicas de negociação sexual, em distintos contextos de relações interpessoais e parcerias afetivo-sexuais. Falar em negociação sexual não significa adotar a perspectiva do individualismo metodológico, que reduz a complexidade envolvida nos processos de performance e gestão da sexualidade a uma mera troca de interesses entre indivíduos. Ao contrário, trata-se de considerar que a aproximação e as interações sexuais entre parceiros envolvem uma intensa dinâmica de negociação acerca de sentidos, desejos e práticas. A noção de negociação sexual evidencia que as possibilidades e formas de enunciar o desejo e interagir sexualmente são condicionadas por contextos socioculturais específicos de interação, refletindo jogos de poder que as relações de gênero e a sexualidade comportam ${ }^{19}$. Indo além, é imperativo ter em conta o caráter polissêmico das categorias utilizadas nas pesquisas.

Questões relacionadas à violência exigem dos pesquisadores o esforço de considerar o caráter construído e historicamente datado do que será assim qualificado em momentos específicos ${ }^{1}$. Esse ol har relativista, que muitas vezes confronta nos- 
sas sensibilidades, torna difícil a operacional ização do estudo, sendo necessário estabelecer critérios arbitrários de definição do que seria - ou não apropriado classificar como violência nos cenários culturais estudados. Ademais, a análise dos resultados encontrados devetomar em conta as possibilidades de enunciação diante das questões colocadas. As expectativas que norteiam o encontro entre entrevistadores e informantes podem influenciar as respostas àquelas perguntas entendidas como pondo em cheque o status social dos sujeitos. No caso de pesquisas quantitativas, é ainda mais complicado lidar com esse tipo de "problema" analítico-metodológico, já que trabalhar com questionários, sobretudo estruturados, implica não saber quais os sentidos acionados pel os sujeitos em suas respostas.

Os dados obtidos se restringem às opções de resposta pré-concebidas pelos pesquisadores, de maneira que se torna impossível apreender como as perguntas e as respostas fornecidas foram interpretadas pelos informantes por ocasião da entrevista. $\mathrm{Na}$ tentativa de superar, ainda que parcialmente, tais limitações, a elaboração do inquérito populacional GRAVAD, a partir deum estudo prévio qualitativo, permitiu acesso àquelas categorias mais familiares aos entrevistados no que concerne às situações que se pretendia investigar. Acrescente-se que a escolha por abordar o tema tanto diretamente quanto de forma menos explícita evidenciou a plasticidade da categoria insistência, queserá melhor discutida adiante.

Cabe destacar que o presente artigo destoa de parte da produção internacional sobre o tema da coerção sexual não só por considerar a questão de uma perspectiva mais ampla acerca da negociação sexual, como também por compreender que o jogo sexual e amoroso comporta consensos e dissensos em torno das práticas de interação. Assim, em vez de utilizarmos categorias como vítima eagressor/a, que denotam uma oposição entre passividade e agência, privilegiamos os termos autor/a e alvo de coerção, ainda quetais designações possam ser também discutíveis. $N$ ão se trata de destituir de legitimidade as experiências de vitimização dos sujeitos que foram forçados a ter relações sexuais contra vontade mediante violência física ou ameaças. N ossa abordagem toma em conta que o sexo forçado aquele que ocorre por constrangimento ou contra vontade- podeassumir ou não essesignificado para os entrevistados, em distintos momentos. Valeacrescentar que seu sentido éconstantementenegociado antes, durante e após as interações, bem como ao longo das trajetórias individuais.

\section{Resultados}

\section{População do estudo}

No universo de 4.634 informantes da etapa quantitativa da pesquisa GRAVAD, $93 \%$ dos rapazes e $81,6 \%$ das moçasjá haviam seiniciado sexualmente. A proporção de informantes com renda familiar mensal per capita menor ou igual a $\mathrm{R} \$ 180,00$ (valor do salário mínimo naépoca do estudo) foi de $25,5 \%$ em Porto Alegre, $27,9 \%$ no Rio de Janeiro e $56,3 \%$ em Salvador $(p=0,0000)$. Porto Alegretambém foi a capital onde encontramos o maior índice de jovens com nível superior de escolaridade - mesmo que incompleto - (34,8\%). No Rio de aneiro, esseíndice foi de $26,4 \%$ e em Salvador, $14,8 \%$ (Tabela 1 ).

0 índice de respostas afirmativas à questão "Alguém já tentou forçar você a ter relações sexuais contra a vontade?" foi superior a $10 \%$, tendo sido constatada maior prevalência entre os participantes do sexo feminino $(16,5 \%)^{20}$. Rapazes e moças residentes em Salvador relataram cerca de três vezes mais experiências de coerção sexual do que os moradores de Porto Alegre ${ }^{20}$. Os dados indicam que fatores como escolaridade e renda familiar per capita estão associados à maior incidência de interações sexuais forçadas entre os entrevistados. N esse sentido, sobressaem diferenças significativas quanto à distribuição de renda ea escolaridade nas três cidades investigadas.

0 perfil das experiências de rapazes e moças é muito distinto: para eles, o autor da coerção tende a ser classificado como uma amiga, com idadeinferior a vinte anos completos; já para elas, se trata de homens de vinte anos ou mais, com quem mantinham/mantêm parcerias afetivo-sexuai $s^{20}$. Cerca de $20,9 \%$ dos rapazes entrevistados afirmaram que 0 autor da coerção foi uma pessoa de mesmo sexo, enquanto para as moças isso ocorreu em aproximadamente $0,5 \%$ dos casos. 0 intercurso sexual foi a consequência da coerção em $19,6 \%$ das situações reportadas por mulheres e em $26,8 \%$ das declarações masculinas.

A opção muita insistência foi a forma de coerção mais assinalada por jovens de ambos os se$\mathrm{xos}^{20}$. Entretanto, é relevante apontar que ela foi referida em quase todas as respostas dos rapazes $(94,1 \%)$ e que somente $3,6 \%$ deles afirmaram terem sido forçados a ter relações sexuais mediante ameaça ou uso de violência física. Para as mulheres, essesíndices foram de $66,6 \%$ e 25,8\%, respectivamente $^{20}$. Isto é, aproximadamente $1 / 4$ das entre vistadas foi vítima de estupro, o que denota que a violência sexual em sua face mais severa é dirigida quase que exclusivamente às mulheres. 
Tabela 1. Distribuição percentual dos entrevistados, segundo nível de escolaridade e renda familiar mensal per capita, por sexo e cidade - Jovens de 18 a 24 anos de Porto Alegre, Rio de Janeiro e Salvador, Brasil, 2002.

\begin{tabular}{|c|c|c|c|c|c|c|c|c|c|}
\hline \multirow{3}{*}{ SEXO } & \multirow{3}{*}{ ESCOLARIDADE DO JOVEM } & \multicolumn{6}{|c|}{ CIDADE } & \multirow{2}{*}{\multicolumn{2}{|c|}{ TOTAL }} \\
\hline & & \multicolumn{2}{|c|}{ Porto Alegre } & \multicolumn{2}{|c|}{ Rio deJaneiro } & \multicolumn{2}{|c|}{ Salvador } & & \\
\hline & & $\mathrm{n}$ & $\%$ & $\mathrm{n}$ & $\%$ & $\mathrm{n}$ & $\%$ & $\mathrm{n}$ & $\%$ \\
\hline \multirow[t]{5}{*}{ Mulheres } & & 694 & & 811 & & 929 & & 2434 & \\
\hline & Fundamental incompleto & & 14,9 & & 17,6 & & 22,4 & & 18,7 \\
\hline & Fundamental completo & & 22,8 & & 24,9 & & 29,2 & & 26,0 \\
\hline & M édio completo & & 31,6 & & 33,5 & & 36,6 & & 34,2 \\
\hline & Superior (incompleto/completo) & & 30,7 & & 24,0 & & 11,8 & & 21,1 \\
\hline \multirow[t]{6}{*}{ Homens } & & 737 & & 718 & & 725 & & 2180 & \\
\hline & Fundamental incompleto & & 22,3 & & 21,9 & & 34,3 & & 25,6 \\
\hline & Fundamental completo & & 21,6 & & 29,7 & & 29,4 & & 28,5 \\
\hline & M édio completo & & 29,8 & & 29,4 & & 26,1 & & 28,5 \\
\hline & Superior (incompleto/completo) & & 26,2 & & 19,0 & & 10,2 & & 17,4 \\
\hline & $\begin{array}{c}\text { RENDA FAMILIAR MENSAL } \\
\text { PER CAPITA* }\end{array}$ & & & & & & & & \\
\hline \multirow[t]{6}{*}{ Mulheres } & & 699 & & 815 & & 933 & & 2447 & \\
\hline & & & 9,7 & & 10,8 & & 29,0 & & 16,3 \\
\hline & M uito baixa (até $R \$ 90,00$ ) & & 19,1 & & 19,0 & & 30,4 & & 22,5 \\
\hline & Baixa $(R \$ 91,00$ a $R \$ 180,00)$ & & 34,5 & & 45,2 & & 26,8 & & 38,1 \\
\hline & M édia $(R \$ 181,00$ a $R \$ 540,00)$ & & 36,7 & & 25,1 & & 13,8 & & 23,1 \\
\hline & Alta (acima de $\mathrm{R} \$ 540,00$ ) & & & & & & & & \\
\hline \multirow[t]{5}{*}{ Homens } & & 739 & & 719 & & 728 & & 2186 & \\
\hline & M uito baixa (até $R \$ 90,00$ ) & & 7,5 & & 8,2 & & 28,9 & & 14,2 \\
\hline & Baixa $(R \$ 91,00$ a $R \$ 180,00)$ & & 14,7 & & 17,9 & & 24,1 & & 19,3 \\
\hline & M édia $(R \$ 181,00$ a $R \$ 540,00)$ & & 40,1 & & 44,5 & & 31,9 & & 40,2 \\
\hline & Alta (acima de $\mathrm{R} \$ 540,00$ ) & & 37,8 & & 29,4 & & 15,1 & & 26,3 \\
\hline
\end{tabular}

Fonte: Pesquisa GRAVAD, 2002.

Nota: $(*)$ Categorias definidas com baseno salário mínimo nacional à época $(\mathrm{R} \$ 180,00)$.

Neste artigo, separamos o conjunto dos informantes em duas sub-amostras: a sub-amostra 1 é composta pelos entrevistados de ambos os sexos que relataram experiências de constrangimento sexual; e a sub-amostra 2, pelos que afirmam nuncaterem vivenciado essetipo de evento. Em seguida, analisamos as experiências de mulheres e homens segundo os meandros da negociação em suas relações sexuais.

\section{Os matizes da negociação sexual}

Em geral, os informantes de ambas as subamostras afirmaram ter prazer em suas interações sexuais (Tabela 1). Cerca de $84 \%$ dos jovens inseridos na sub-amostra 1 e $91,8 \%$ dos que não relataram experiências de coerção sexual afirmam estar satisfeitos com suas vidas sexuais. Contudo, o percentual de rapazes e moças que já foram alvo de constrangimento sexual que referiu estar pouco ou não satisfeito é quase duas vezes maior daquele encontrado na sub-amostra 2 ( $15,2 \%$ e $8,1 \% ; p=$ $0,0004)$. Quando apreciamos separadamente as respostas dos entrevistados por sexo, verificamos que tal resultado se deve à maior insatisfação sexual entre as jovens que relatam coerção, comparativamente às moças que não sofreram tal constrangimento (os percentuais são de $16,9 \%$ e 7,9\%, respectivamente; $p=000,1)$; não há diferença significativa entre as respostas masculinas (Tabela 2).

As opiniões sobre sexo não variaram significativamente em razão dos informantes terem vivenciado ou não experiências desexo forçado. A maioria dos jovens optou por definir o sexo como pro- 
Tabela 2. Satisfação e prazer nas relações sexuais segundo sexo e experiência de coerção sexual ao longo da vida - Jovens de 18 a 24 anos de Porto Alegre, Rio de Janeiro e Salvador, Brasil, 2002.

\begin{tabular}{|c|c|c|c|c|c|c|c|c|c|}
\hline \multirow{3}{*}{$\begin{array}{l}\text { Satisfação e prazer } \\
\text { nas relações sexuais }\end{array}$} & \multicolumn{3}{|c|}{ Mulheres } & \multicolumn{3}{|c|}{ Homens } & \multicolumn{3}{|c|}{ Total } \\
\hline & \multicolumn{2}{|c|}{ Relações coercitivas } & \multirow{2}{*}{$\begin{array}{c}p \\
\text { valor }\end{array}$} & \multicolumn{2}{|c|}{ Relações coercitivas } & \multirow{2}{*}{$\begin{array}{c}p \\
\text { valor }\end{array}$} & \multicolumn{2}{|c|}{ Relações coercitivas } & \multirow{2}{*}{$\begin{array}{c}p \\
\text { valor }\end{array}$} \\
\hline & $\operatorname{Sim}(\%)$ & Não (\%) & & $\operatorname{Sim}(\%)$ & Não (\%) & & $\operatorname{Sim}(\%)$ & Não (\%) & \\
\hline \multirow{2}{*}{\multicolumn{10}{|c|}{$\begin{array}{l}\text { Quanto a sua vida } \\
\text { sexual, você se sente }\end{array}$}} \\
\hline & & & & & & & & & \\
\hline Satisfeito & 83,09 & 92,08 & & 87,21 & 91,61 & & 84,76 & 91,83 & \\
\hline Pouco ou insatisfeito & 16,91 & 7,92 & & 12,79 & 8,39 & & 15,24 & 8,2 & \\
\hline $\mathrm{n}$ & 351 & 1635 & 0,000 & 195 & 1835 & 0,222 & 546 & 3470 & 0,0004 \\
\hline \multirow{2}{*}{\multicolumn{10}{|c|}{$\begin{array}{l}\text { Você tem prazer } \\
\text { nas suas relações sexuais }\end{array}$}} \\
\hline & & & & & & & & & \\
\hline Sim & 92,8 & 96,9 & & 99,64 & 98,68 & & 95,59 & 97,86 & \\
\hline Não & 7,2 & 3,1 & & 0,36 & 1,32 & & 4,4 & 2,1 & \\
\hline $\mathrm{n}$ & 351 & 1634 & 0,029 & 196 & 1838 & 0,128 & 547 & 3471 & 0,0310 \\
\hline
\end{tabular}

va de amor pelo/a parceiro/a ou fonte de prazer e satisfação pessoal (87\%) em detrimento de uma perspectiva fisicalista - sexo como necessidade física. Prevalece também a noção de que é possível controlar a vontade de ter sexo (87\%), o que refuta a noção de desejo sexual como algo incontrolável. Cerca de $52,87 \%$ dosinformantes da sub-amostra 1 e 50,4\% dos que se inserem na sub-amostra 2 acreditam que os homens têm mais necessidade de sexo (categoria nativa que expressa a idéia de queo sexo é um impulso natural, que pode ser mais ou menos controlável) do que as mulheres; $42,9 \%$ e $45,5 \%$, respectivamente, acreditam que homens e mulheres têm a mesma necessidade de sexo (dados não apresentados).

No que tange à negociação sexual, os entrevistados de ambas as sub-amostras tendem a afirmar se sentir à vontade para expressar ao/à parceiro/a suas preferências e desejos sexuais. Quando indagados acerca de investidas sexuais indesejadas, os jovens da sub-amostra 1 tenderam a relatar não ceder aos apelos dos(as) parceiros(as) em uma proporção maior que aqueles sem experiências de coerção sexual. Um dado curioso équecerca de $12,59 \%$ dos rapazes e moças que reportam al guma forma de constrangimento sexual declarem nunca terem vivenciado um episódio em que não quisessem fazer sexo e seus parceiros, sim. 0 exame dos dados segundo a variável gênero revelou que $57,7 \%$ dos rapazes da sub-amostra 1 afirmaram que não cedem aos avanços sexuais indesejados de suas parceiras, enquanto somente $36,6 \%$ dos quenunca fo- ram alvo de coerção sexual referiram o mesmo. De modo similar, foi inesperado queapenas $56,3 \%$ dos jovens da sub-amostra 1 tenham assinal ado que já houve ocasiões em que se sentiram pressionados a fazer "coisas" das quais não gostam durante o sexo. Acrescente-se que $20 \%$ dos informantes da subamostra 2 responderam afirmativamente a essa questão. A proporção de moças da sub-amostra 1 que declararam nunca ter vivenciado situações em que já se sentiram pressionadas a fazer coisas das quais não gostam durante o sexo foi superior à dos rapazes (63\% e 53,4\%, respectivamente) (Tabela 3).

Quanto a possíveis dissensos na negociação sexual, uma parcela reduzida dos rapazes das duas sub-amostras assinalaram nunca ter ocorrido situações em que desejaram ter relações sexuais e al guma de suas parceiras, não. Contudo, os informantes da sub-amostra 1 tendem a referir mais que os da sub-amostra 2 esse tipo de episódio (87,07\% e 74,78\%, respectivamente). A apreciação exclusiva das respostas femininas indicou que $55,69 \%$ das moças da sub-amostra 1 e $61,28 \%$ das informantes da sub-amostra 2 - ou seja, mais da metade das mulheres entrevistadas, - afirmaram que nunca houve uma ocasião em que quisessem transar e seus parceiros tenham se recusado. Entre os homens e mulheres das duas sub-amostras que responderam afirmativamente à questão, predominou como reação diante da recusa sexual a postura de tentar convencer o parceiro a repensar a decisão, usando de diálogo, insistência ou sedução (Tabela 3). 
Tabela 3. Descritores da negociação sexual segundo sexo e experiência de coerção sexual ao longo da vida - Jovens de 18 a 24 anos de Porto Alegre, Rio de Janeiro e Salvador, Brasil, 2002.

\begin{tabular}{|c|c|c|c|c|c|c|c|c|c|}
\hline \multirow{3}{*}{$\begin{array}{l}\text { Variáveis sobre negociação } \\
\text { sexual }\end{array}$} & \multicolumn{3}{|c|}{ Mulheres } & \multicolumn{3}{|c|}{ Homens } & \multicolumn{3}{|c|}{ Total } \\
\hline & \multicolumn{2}{|c|}{ Relações coercitivas } & \multirow{2}{*}{$\begin{array}{c}p \\
\text { valor }\end{array}$} & \multicolumn{2}{|c|}{ Relações coercitivas } & \multirow{2}{*}{$\begin{array}{c}p \\
\text { valor }\end{array}$} & \multicolumn{2}{|c|}{ Relações coercitivas } & \multirow{2}{*}{$\begin{array}{c}p \\
- \text { valor }\end{array}$} \\
\hline & $\operatorname{Sim}(\%)$ & Não (\%) & & $\operatorname{Sim}(\%)$ & Não (\%) & & $\operatorname{Sim}(\%)$ & Não (\%) & \\
\hline \multicolumn{10}{|c|}{$\begin{array}{l}\text { Durante a relação sexual, já se } \\
\text { sentiu pressionado/a pelos/as } \\
\text { parceiros/as a fazer coisas que } \\
\text { não gosta }\end{array}$} \\
\hline Sim & 63,01 & 26,14 & & 46,52 & 14,9 & & 56,31 & 20,06 & \\
\hline Não & 36,99 & 73,86 & & 53,48 & 85,1 & & 43,69 & 79,94 & \\
\hline $\mathrm{n}$ & 351 & 1634 & 0,0000 & 195 & 1838 & 0,0000 & 546 & 3472 & 0,0000 \\
\hline \multicolumn{10}{|l|}{$\begin{array}{l}\text { Quando não está com vontade } \\
\text { de ter relações sexuais com } \\
\text { parceiro/a, você }\end{array}$} \\
\hline Cede & 32,63 & 22,39 & & 24,24 & 27,66 & & 29,2 & 25,23 & \\
\hline Não cede & 58,87 & 65,5 & & 57,27 & 36,09 & & 58,21 & 49,61 & \\
\hline I sso nunca aconteceu & 8,502 & 12,11 & & 18,49 & 36,25 & & 12,59 & 25,15 & \\
\hline $\mathrm{n}$ & 350 & 1632 & 0,0053 & 196 & 1830 & 0,0001 & 546 & 3462 & 0,0001 \\
\hline \multicolumn{10}{|l|}{$\begin{array}{l}\text { Durante a relação sexual, você } \\
\text { se sente à vontade para pedir } \\
\text { ao/à parceiro/a que faça as } \\
\text { coisas que você mais gosta }\end{array}$} \\
\hline Sim & 85,63 & 91,26 & & 93,73 & 95,81 & & 88,95 & 93,72 & \\
\hline Não & 14,37 & 8,74 & & 6,271 & 4,19 & & 11,05 & 6,28 & \\
\hline $\mathrm{n}$ & 350 & 1629 & 0,0220 & 196 & 1835 & 0,5197 & 546 & 3464 & 0,0134 \\
\hline \multicolumn{10}{|l|}{$\begin{array}{l}\text { Já houve ocasiões em que você } \\
\text { desejava ter relações sexuais e } \\
\text { seu/sua parceiro/a não }\end{array}$} \\
\hline Sim & 44,31 & 38,73 & & 87,07 & 74,78 & & 61,62 & 58,16 & \\
\hline Não & 55,69 & 61,27 & & 12,93 & 25,22 & & 38,38 & 41,84 & \\
\hline $\mathrm{n}$ & 351 & 1633 & 0,1042 & 195 & 1829 & 0,0282 & 546 & 3462 & 0,2370 \\
\hline \multicolumn{10}{|l|}{$\begin{array}{l}\text { Na última vez em que isso } \\
\text { aconteceu, você }\end{array}$} \\
\hline $\begin{array}{l}\text { Tentou conversar, seduziu, } \\
\text { insistiu }\end{array}$ & 63,72 & 69,63 & & 80,33 & 74,55 & & 73,25 & 73,06 & \\
\hline $\begin{array}{l}\text { Ficou quieto/a e não falou no } \\
\text { assunto }\end{array}$ & 36,28 & 30,37 & & 19,67 & 25,45 & & 26,75 & 26,94 & \\
\hline $\mathrm{n}$ & 166 & 593 & 0,3187 & 165 & 1367 & 0,2568 & 331 & 1960 & 0,9562 \\
\hline \multicolumn{10}{|l|}{$\begin{array}{l}\text { Já houve ocasiões em que } \\
\text { algum parceiro/a quis ter } \\
\text { relações sexuais e você não }\end{array}$} \\
\hline Sim & 84,63 & 79,92 & & 77,82 & 47,93 & & 81,85 & 62,61 & \\
\hline Não & 15,37 & 20,08 & & 22,18 & 52,07 & & 18,15 & 37,39 & \\
\hline $\mathrm{n}$ & 351 & 1633 & 0,1793 & 196 & 1838 & 0,0000 & 547 & 3471 & 0,0000 \\
\hline \multicolumn{10}{|l|}{$\begin{array}{l}\text { Na última vez em que isso } \\
\text { aconteceu, ele/a }\end{array}$} \\
\hline $\begin{array}{l}\text { Tentou conversar, seduziu, } \\
\text { insistiu }\end{array}$ & 87,53 & 75,9 & & 91,0 & 80,86 & & 88,9 & 77,94 & \\
\hline $\begin{array}{l}\text { Ficou quieto/a e não falou no } \\
\text { assunto }\end{array}$ & 12,47 & 24,1 & & 9,0 & 19,14 & & 11,1 & 22,06 & \\
\hline $\mathrm{n}$ & 279 & 1275 & 0,0061 & 150 & 857 & 0,1292 & 429 & 2132 & 0,0028 \\
\hline
\end{tabular}

Fonte: Pesquisa GRAVAD, 2002. 
Ao considerarmos a situação inversa - isto é, se al gum/a parceiro/a já quis ter relações sexuais e ele/a não -, evidencia-se que nem todos os entrevistados inseridos na sub-amostra 1 responderam afirmativamente à questão. 0 exame dos dados por gênero revelou não haver diferença significativa entre as declarações femininas: moças de ambas as sub-amostras tenderam a afirmar já ter vivenciado episódios em que algum parceiro quister relações sexuais e elas não. Cerca de $3 / 4$ dosjovens que relataram ter sido coagidos ao sexo afirmaram ter vivenciado esse tipo de situação. M aisuma vez, os dados surpreendem, ao evidenciar que quase metade dos rapazes inseridos na sub-amostra 2 $(47,9 \%)$ reportam o mesmo. Aproximadamente $88,9 \%$ dos entrevistados da sub-amostra 1 e $77,94 \%$ de rapazes e moças da sub-amostra 2 relataram que, na ocasião, seus parceiros tentaram convencê-los a mudar de idéia através de insistência e tentativas de sedução. Para os rapazes de ambas as sub-amostras, essa reação de suas parceiras foi um pouco mais frequente do que para as moças (Tabela 3).

\section{Discussão}

N este trabalho, consideramos a gestão das relações sexuais pelos entrevistados a partir de dois eixos: 0 prazer/satisfação sexual e a recusa ao sexo. Entendemos queessas são as dimen sões mais diretamente implicadas na configuração de determinados comportamentos e atitudes sexuais como forçados nos contextos específicos deinteração. Ten do em vista a importância do gênero na construção de formas de ser e estar no mundo e, portanto, nos processos de diferenciação e na modelação de condutas sociais ${ }^{19,22,23}$, examinamos os dados segundo essa variável. Buscamos pensar como papéis e convenções locais acerca dos gêneros se refletem nos valores e na negociação em torno do sexo.

A comparação entre os jovens da sub-amostra 1 e o conjunto dos rapazes e moças inseridos na sub-amostra 2 revelou similaridade no que concerne aos valores sobre sexualidade. Os entrevistados se dividem entre a noção de atividade sexual como algo profundamente imbricado com a afetividade e a reciprocidade constitutivas das relações amorosas e sua compreensão como "fonte de prazer e satisfação pessoal". Esse resultado é similar ao encontrado na etapa qualitativa da pesquisa ${ }^{3}$. Embora a categoria nativa necessidade de sexo indique que a noção de desejo sexual como necessidade física se encontra presenteno imaginário destes jovens, quando indagados diretamente sobre 0 as- sunto, os participantes do inquérito populacional privilegiaram os aspectos relacional ou de satisfação pessoal envolvidos na atividade sexual. Em consonância, prevalece a noção de que o desejo sexual pode ser gerido pela vontade individual e $32,65 \%$ e $22,39 \%$ dos jovens das sub-amostras 1 e 2 , respectivamente, afirmaram ceder aos desejos dos/as parcei ros/as mesmo quando estão sem vontade de transar.

Quase 2/3 dos informantes inseridos na subamostra 2 declararam que já aconteceu de al gum/a parceiro/a querer ter relações sexuais quando não estavam com vontade, e 75,9\% deles relataram que a recusa teve como contrapartida tentativas deconvencimento por estratégias variadas; dentre elas, a insistência. Como vimos, a insistência aparece como uma das formas de constrangimento sexual quando perguntamos "Alguém já tentou forçar você a ter relações sexuais contra vontade?" Chama atenção que 14 dos 33 entrevistados que relataram haverem sido coagidos a ter relações sexuais, em razão da intolerância dos/as parceiro/as frente à recusa, tenham assinalado que nunca sofreram coerção sexual. Q uando consideramos a reação dos informantes diante de situações em que seus parceiros negaram investidas sexuais, cerca de $73 \%$ deles declararam que, insatisfeitos com a rejeição, buscaram obter o consentimento sexual por meio de diálogo, insistência e sedução (8 entrevistados reportaram terem obrigado seus parceiros a ter relações sexuais - seis eram do sexo feminino). Tais resultados, a nosso ver, só podem ser compreendidos sob a ótica dos processos de gestão das interações sexuais em contextos de relacionamento ${ }^{8,9}$. Esses processos - complexos, fluidos e dinâmicos - se constroem, reproduzem e transformam nas interações entre os sujeitos eentre eles e as convenções sociais, envolvendo acomodações, resistências e reinvenções ${ }^{1,19}$. As tentativas de convencimento de um/a parceiro/a, face à recusa ao sexo, podem ou não ser entendidas como formas decoerção sexual, deacordo com: o contexto em que o evento ocorreu, o tipo de parceria, a maior ou menor disposição dosindivíduos a discutir suas preferências ebarganhar seus desejos em situações diversas e as estratégias que se podelançar mão em uma dada situação ${ }^{3}$. Ademais, é relevante destacar que a insistência e a sedução são práticas de negociação sexual ambíguas. Elas se situam nas fronteiras entre 0 direito à livre expressão da vontadeindividual eo cerceamento da liberdade do outro. Essa ambiguidadeéonipresentenos roteiros de interação afetivo-sexual entre os gêneros no Brasil ${ }^{22,23}$.

A literatura sócio-antropológica aponta que o estabelecimento de parcerias e a conquista sexual 
envolvem um jogo de sedução em que aos homens cabe o papel de tomar a iniciativa, tentar obter contatos sexuais de suas parceiras, sem desistir diante de recusa inicial; já as mulheres devem se mostrar inexperientes e pouco predispostas ao sexo, gerir os avanços sexuais masculinos e permitir intimidades à medida em que se estabelece 0 vínculo com o parceiro ${ }^{22,23}$. Embora esse roteiro seja flexível ea criatividade dos atores em interação repercuta em variadas apropriações e desdobramentos dessas convenções ${ }^{1}$, predomina a premissa do sexo como algo almejado pelos homens e que é consentido/concedido pelas mulheres ${ }^{3,22}$. A ambiguidade entrenegociação e coerção é, de certo modo, intrínseca a esse jogo e o s sujeitos podem ter dificuldades em precisar quando a recusa da parcei ra representa de fato uma interdição. A permissividade inicial para com os avanços masculinos pode ser entendida como indicativa de desejo sexual e daintenção deter relações sexuais, mesmo quando após uma aproximação inicial ocorre a recusa do sexo ${ }^{10,16}$.

Os códigos de gênero acarretam alguns limites à autonomia masculina nos processos de negociação sexual5,18, o que é bem sintetizado pelo ditado popular de que "homem que é homem, não nega fogo". Na fase qualitativa da pesquisa GRAVAD, por exemplo, a mai oria dos rapazes com experiências de constrangimento sexual relatou episódios em que a recusa ao sexo teve como consequência o questionamento de sua virilidade por parceiras se xuais e/ou pelo grupo de pares ${ }^{3}$. Cáceres ${ }^{18}$, ao investigar experiências de sexo "não-consensual" entre homens e mulheres jovens de classe trabalhadora e camadas médias em três cidades peruanas (Lima, Chiclayo e Trujillo), encontrou dados similares. Nos relatos masculinos sobre episódios de coerção sexual em que 0 autor do constrangimento era do sexo feminino, as experiências de sexo forçado foram associadas a interações sexuais com mulheres mais velhas e/ou atribuída à incapacidade do rapaz constrangido de satisfazer sexualmente a parceira. Quando a coerção é perpetrada por um indivíduo do mesmo sexo, o constrangimento tendeaser percebido mais diretamente como violência sexual e como algo capaz de feminilizar o rapaz coagido, podendo implicar desejos homossexuais ${ }^{18}$. Essa análise fornece pistas importantes para a compreensão do porquê a muita insistência ser tão referida em nosso estudo como estratégia utilizada para forçar os homens a terem relações sexuais. A insistência excessiva das parceiras, diante da recusa ao sexo, promove um tipo de inversão hierárquica no jogo de sedução e coloca em foco a indisposição dos rapazes para a ativida- de sexual, causando desconforto em suas identidades de gênero. Assim, travar contatos ou intercursos sexuais mediante essa forma de pressão moral pode ser percebido pelos homens como um constrangimento da vontade ${ }^{5}$.

Os significados sexuais relacionados ao feminino eao masculino modelam as práticas sexuais ${ }^{1}$, condicionando os processos denegociação em torno do sexo - o que se negocia, o que é possível negociar e com quem ${ }^{19}$. Evidenciam, assim, as nuances nas relações de poder entre os gêneros ${ }^{19}$. Os resultados indicam que o sexo contra vontade pode ser vivenciado de formas variadas; comportamentos e atitudes passíveis de serem caracterizados como restrições à vontade individual podem ser percebidos como constituindo o leque de práticas denegociação sexual, em um determinado contexto sociocultural ${ }^{3}$. Entretanto, é relevante enfatizar que identificamos, na sub-amostra 1, 61 casos de estupro - entendido de modo mais restrito como o intercurso sexual forçado mediante o uso ou ameaça de uso de violência física - dentre os quais três vítimas eram do sexo masculino. A maioria desses episódios ocorreu quando os entrevistados tinham entre os 14 e 18 anos de idade eo perpetrador, entre 20 e 29 anos. Ao contrário do que se poderia imaginar, o agressor em um dos casos envolvendo vítimas do sexo masculino foi uma mulher, classificada pelo informante como desconhecida e com idade aproximada a sua - el e tinha 20 anos à época do evento e a agressora, 19 anos. Esses resultados serão apresentados na íntegra e discutidos da maneira devida em uma próxima oportunidade.

\section{Consideraçõesfinais}

Parte da literatura sobre coerção sexual e alguns documentos internacionais afinados com o ideário dos direitos humanos fazem ressal vas à postura relativista frente a comportamentos associados a certas modalidades de violência ${ }^{2,4}$. Contudo, deve-se enfatizar que éo confronto entre conceitos pré-estabelecidos e experiências distintas e específicas que possibilita a reflexão crítica acerca de fenômenos sociais. Ao discutir os resultados sobre coerção e negociação sexual coletados na etapa quantitativa da pesquisa GRAVAD, este artigo pretendeu demonstrar a multiplicidade de sentidos envolvidos na configuração de situações de conflito na negociação sexual enquanto experiências de sexo forçado. Essa multiplicidadeér reflexo dos valores sexuais que orientam as performances de gêneros em roteiros sexuais variados. A complexida- 
de dos processos de gestão da sexualidade evidencia que práticas sociais não possuem sentidos intrínsecos; os significados se constroem continuamente em meio às interações. Por isso, a importância de buscarmos compreender quefatores convergem para que al go percebido como constrangimento sexual seja ou não considerado aceitável, legítimo ou "natural" em determinados cenários culturais. Tal entendimento pode dificultar a construção de uma perspectiva global do problema; porém, é imprescindível na abordagem de situações cotidianas concretas.

\section{Colaboradores}

F Cordeiro desenvolveu a concepção do artigo, realizou a pesquisa bibliográfica, análise e interpretação dos dados e a redação o texto. M L H eilborn trabalhou na concepção do quadro teórico, execução da pesquisa e redação do texto e fez a revisão final do artigo. CS Cabral efetuou o processamento dos dados e contribuiu na concepção do artigo, análise dos resultados e na revisão final do texto. CL M oraes trabalhou no processamento dos dados e na edição do texto.

\section{Referências}

1. Gagnon J. U ma interpretação do desejo: ensaios sobre o estudo da sexualidade. Rio de Janeiro: Garamond; 2006.

2. Heise L, Moore K, Toubia N. Sexual coercion and reproductive health, a focus on research. Populational Council Health [website]. 1995[cited $2008 \mathrm{~N}$ ov 10]: [about 64 p.]. Available from: http://www.popcouncil. org/pdfs/scoer.pdf

3. Cordeiro F. N egociando significados: coerção sexual em narrativas de jovens brasileiros [dissertação]. Rio de Janeiro (RJ): Universidade do Estado do Rio de Janeiro; 2008.

4. Krug EG, Dahlber LL, M ercy JA, Zwi AB, Lozano R. World Report on Violence and Health. Geneva: World Health Organization; 2002.

5. Waldner L, Vaden L, Sikka A. Sexual coercion in India: an exploratory analysis using demographic variables. Archs Sex Behav 1999; 28(6):523-538.

6. Jejeebhoy S, Bott $\mathrm{S}$. N on-consensual experiences of young people in developing countries: an overview. In: Jejeebhoy S, Bott S, editors. Sex without consent: young people in developing countries. New York: ZedBooks; 2005. p. 3-44.

7. Fiebert MS, Osburn K. Effect of gender and ethnicity on self reports of mild, moderate and severe sexual coercion. Sexuality \& Culture 2001; 1(5):3-11.

8. Faulkner GE, Kolts RL, Hicks GF. Sex role ideology, relationship context, and response to sexual coercion in college females. Sex Roles 2008; 59:139-150.

9. Starratt VG, Goertz AT, Shackelford TK, McKibbin WF, Stewart-William S. M en's partner-directed insults and sexual coercion in intimate relationship. J Fam Viol 2008; 23:315-323.

10. Lottes IL, Weinberg MS. Sexual coercion among university students: a comparison of the United States and Sweden. J Sex Res 1997; 34(1):67-76.

11. Kalmuss D. Nonvolitional sex and sexual health. Arch Sex Beh 2004; 33(3):197-209.

12. Alksnis C, Desmarais S, Senn C, Hunter N. M ethodologic concerns regarding estimates of physical violence in sexual coercion: overstatement or understatement? Archs Sex Behav 2000; 29(4):323-334. 
13. Reichenheim M, M oraes CL. Cross-cultural measurement equivalence of the Revised Conflict Tactics Scales (CTS2) Portuguese version used to identify violence within couples. Cad. Saude Publica 2002; 18(3):783-796.

14. Struckman-Johnson C, Struckman-Johnson D. Sexual coercion reported by women in three Midwestern prisons. J Sex Res 2002; 39(3):217-227.

15. Struckman-Johnson C, Struckman-Johnson D, Rucker L, Bumby K, Donaldson S. Sexual coercion reported by men and women in prisons. J Sex Res 1996; 33(1):67-76.

16. Sprecher S, Hatfield DE, Cortese A, Potapova E, Levitskaya A. Token resistance to sexual intercourse and consent to unwanted sexual intercourse: college students' dating experiences in three countries. J Sex Res 1994; 31(2):125-132.

17. Struckman-Johnson C, Struckman-Johnson D. Men's reactions to hypothetical forceful sexual advances from women: the role of sexual standards, relationship availability, and the beauty bias. Sex Roles 1997; 37(5-6):319-333.

18. Cáceres $C$. Assessing young people's non-consensual sexual experiences. In: Jejeebhoy SJ, Thapa S, editors. Sex without consent: young people in developing countries. New York: ZedBooks; 2005. p. 127-138.

19. Barbosa RM. Negociação sexual ou sexo negociado? Gênero, sexualidade e poder em tempos de AIDS [tese]. Rio de Janeiro (RJ): Universidade do Estado do Rio de Janeiro; 2001.

20. M oraes CL, Cabral CS, Heilborn ML. Magnitude e caracterização de situações de coerção sexual vivenciadas por jovens de três grandes capitais brasileiras: Porto Alegre, Rio de Janeiro e Salvador. Cad. Saude Publica 2006; 22(7):1493-1504.

21. Aquino EML, Araújo MJ, Almeida MC. Aspectos me todológicos, operacionais e éticos da pesquisa GRAVAD. In: Heilborn ML, Aquino EML, Bozon M, Knauth $R D$, organizadores. $O$ aprendizado da sexualidade: reprodução e trajetórias sociais de jovens brasileiros. Rio de Janeiro: Garamond/Fiocruz; 2006. p. 97-136.

22. Bozon M, Heilborn ML. As carícias e as palavras: iniciação sexual no Rio de Janeiro e em Paris. Novos Estudos/CEBRAP 2001; 59:111-135.

23. Heilborn ML. Experiência da sexualidade, reprodução e trajetórias biográficas juvenis. In: Heilborn M L, Aquino EML, Bozon M, Knauth RD, organizadores. 0 aprendizado da sexualidade: reprodução e trajetórias sociais de jovens brasileiros. Rio de Janeiro: Garamond/ Fiocruz; 2006. p. 29-59.

Artigo apresentado em 19/11/2008

Aprovado em 29/01/2009

Versão final apresentada em 18/03/2009 